\title{
S-nitrosylation of the Peroxiredoxin-2 promotes $S$-nitrosoglutathione-mediated lung cancer cells apoptosis via AMPK-SIRT1 pathway
}

Yihan Zhang ${ }^{1,2,3}$, Changning Sun ${ }^{1,2,3}$, Guokai Xiao ${ }^{1,2,3}$, Hui Shan ${ }^{1,2,3}$, Luyao Tang ${ }^{1,2,3}$, Yujiao Yi ${ }^{1,2,3}$, Wengong Yu ${ }^{1,2,3}$ and Yuchao Gu (1) $1,2,3$

\begin{abstract}
Protein S-nitrosylation, the redox-based posttranslational modification of a cysteine thiol by the attachment of a nitric oxide (NO) group, is responsible for a variety of signaling effects. Dysregulation of S-nitrosylation may be directly linked to cancer apoptotic resistance and cancer therapy outcomes, emphasizing the importance of S-nitrosylation in cancer. Peroxiredoxin-2 (Prdx2), an antioxidant enzyme, plays an important role in the protection of cancer cells from oxidative radical damage caused by hydrogen dioxide $\left(\mathrm{H}_{2} \mathrm{O}_{2}\right)$, which is a potential target for cancer therapy. Our studies showed that, as an endogenous NO carrier, S-nitrosog lutathione (GSNO) induced apoptosis in lung cancer cells via nitrosylating $\operatorname{Prdx2}$. The nitrosylation of Prdx2 at Cys51 and Cys172 sites disrupted the formation of Prdx2 dimer and repressed the Prdx2 antioxidant activity, causing the accumulation of endogenous $\mathrm{H}_{2} \mathrm{O}_{2} \cdot \mathrm{H}_{2} \mathrm{O}_{2}$ activated AMPK, which then phosphorylated SIRT1 and inhibited its deacetylation activity toward p53 in A549 cells or FOXO1 in NCl-H1299 cells. Taken together, our results elucidate the roles and mechanisms of Prdx2 S-nitrosylation at Cys51 and Cys172 sites in lung cancer cells apoptosis and this finding provides an effective lung cancer treatment strategy for managing aberrant Prdx2 activity in lung cancers.
\end{abstract}

\section{Introduction}

Lung cancer is one of the most common types of malignancies worldwide with a 5-year survival rate of $<15 \%$. The majority of patients are diagnosed with an incurable advanced/metastatic stage disease ${ }^{1,2}$. To circumvent resistance to apoptosis is a novel strategy for treating tumors ${ }^{3}$. Therefore, a much deeper

\footnotetext{
Correspondence: Wengong Yu (yuwg66@ouc.edu.cn) or

Yuchao Gu (guych@ouc.edu.cn)

${ }^{1}$ Key Laboratory of Marine Drugs, Ministry of Education, School of Medicine and Pharmacy, Ocean University of China, 5 Yushan Road, Qingdao 266003,

China

${ }^{2}$ Laboratory for Marine Drugs and Bioproducts of Qingdao National Laboratory for Marine Science and Technology, Qingdao 266200, China

Full list of author information is available at the end of the article.

Edited by P. Salomoni
}

understanding of key molecular events involving in apoptotic resistance may lead to better diagnosis and treatment.

Protein $S$-nitrosylation is the posttranslational modification of a cysteine by attaching a nitric oxide (NO) group to major classes of proteins ${ }^{4}$. It modulates the function of target proteins through conformational changes, alteration of protein activity, or regulation of protein-protein interactions ${ }^{5}$. Increasing studies have shown that $S$-nitrosylation status may be directly linked to cancer onset, progression, and treatment resistance ${ }^{6}$, highlighting the possibility to develop $S$-nitrosylationrelated anti-cancer therapeutic drugs. As the storage and transport form of NO, S-nitrosoglutathione (GSNO) has been proposed to regulate circulating levels of $\mathrm{NO}$ and NO-derived species ${ }^{7}$. By transferring its $\mathrm{NO}$ moiety to

\section{(c) The Author(s) 2019}

(c) Open Access This article is licensed under a Creative Commons Attribution 4.0 International License, which permits use, sharing, adaptation, distribution and reproduction c. in any medium or format, as long as you give appropriate credit to the original author(s) and the source, provide a link to the Creative Commons license, and indicate if changes were made. The images or other third party material in this article are included in the article's Creative Commons license, unless indicated otherwise in a credit line to the material. If material is not included in the article's Creative Commons license and your intended use is not permitted by statutory regulation or exceeds the permitted use, you will need to obtain permission directly from the copyright holder. To view a copy of this license, visit http://creativecommons.org/licenses/by/4.0/. 
some proteins (trans-nitrosylation) ${ }^{8}$, GSNO plays a crucial role of protein $S$-nitrosylation in both physiological and pathological processes ${ }^{9}$. Besides, GSNO can also protect against oxidative stress in the endothelium, myocardium, brain tissues, and other cells ${ }^{10}$. It is reported that GSNO inhibits STAT3 phosphorylation through $S$ nitrosylation of STAT3, to increase apoptosis of head and neck squamous cell carcinoma cells ${ }^{11}$. However, whether GSNO can also induce apoptosis in other cancer cells (such as lung cancer cells) remains unclear.

Peroxiredoxins (Prdxs) are thiol-specific antioxidant enzymes, which have a class of six antioxidant enzymes (Prdx1-6) in mammals. They are typically classified by the number of cysteinyl residues directly involved in catalysis as 2-Cys (Prdx1-4), atypical 2-Cys (Prdx5), and 1-Cys $(\operatorname{Prdx} 6)^{12}$. Prdx2, widely expressed in various tissues and cells, regulates cell proliferation, apoptosis, and differentiation by altering the intracellular hydrogen peroxide $\left(\mathrm{H}_{2} \mathrm{O}_{2}\right)$ level ${ }^{13,14}$. Excessive $\mathrm{H}_{2} \mathrm{O}_{2}$ induced by abnormal metabolism or anti-tumor drugs leads to damage in cancer cells ${ }^{15}$, which can be inhibited by the overexpression of $\operatorname{Prdx} 2^{16}$, suggesting it may be possible to downregulate the expression or activity of Prdx2 for inhibiting the growth of lung cancer cells. So far, only adenanthin has been reported to induce the death of hepatocellular carcinoma cells through targeting Prdx1/ $2^{17}$. It is demonstrated that nitrosylation affects the status of Prdx2 catalytic cycle, which is involved in cardiomyocyte differentiation of mouse embryonic stem cells induced by $\mathrm{GSNO}^{18}$. Therefore, it should be valuable to explore whether GSNO can regulate Prdx2 activity by nitrosylation and further induce the apoptosis of lung cancer cells.

In this study, we investigated the efficacy of GSNO on lung cancer and the related mechanism. We showed that GSNO nitrosylated Prdx2 at Cys51 and Cys172 sites, which are involved in the formation of homodimer, and inhibited its catalytic cycle, subsequently resulting in local $\mathrm{H}_{2} \mathrm{O}_{2}$ accumulation and further increasing the activity of AMPK. Activated AMPK phosphorylated SIRT1 at Thr344 site, which resulted in the loss of SIRT1 deacetylase activity toward p53 or FOXO1 and further induced lung cancer cell apoptosis. These data may provide new insights into the potential target for lung cancer treatment.

\section{Result}

\section{GSNO induces cell apoptosis in lung cancer cells}

To investigate the effect of GSNO on lung cancer cells, we applied it to A549 and NCI-H1299 cells. The results showed that GSNO decreased cell viability and cell numbers in both A549 and NCI-H1299 cells (Fig. 1a-d, Supplementary Fig. 1a-c). Western blotting (WB) analysis further showed that GSNO promoted the activation of
Caspase-3 (Fig. 1e, Supplementary Fig. 1d), indicating that GSNO induces cell apoptosis in A549 and NCI-H1299 cells. In clonogenic assays, both A549 and NCI-H1299 cells treated by GSNO formed fewer colonies compared with the control groups (Fig. 1f, Supplementary Fig. 1e). Moreover, combined treatment of GSNO with cisplatin or paclitaxel strongly suppressed cell viability in A549 or NCI-H1299 cells, respectively (Fig. 1g, Supplementary Fig. 1f). Taken together, these results indicate that GSNO inhibits cell growth, survival, and colony formation in lung cancer cells. Interestingly, compared with lung cancer cells, normal lung cells (WI38 and BEAS-2B) were less sensitive to GSNO (Supplementary Fig. 2a). Furthermore, GSNO reductase inhibitor N6022 had synergistic effects with GSNO on cell viability and Caspase-3-mediated apoptosis (Fig. 1h, i). We also treated A549 cells with another NO donor called $S$-Nitroso- $N$-acetylpenicillamine (SNAP). As SNAP produced NO with later decomposition time and lower concentration (Supplementary Fig. 2d), it caused similar but slighter effects of Caspase-3-mediated apoptosis compared with GSNO (Supplementary Fig. 2b-e). Lipopolysaccharides (LPS), which could induce inducible NO synthase ${ }^{19}$ and contribute NO production (Supplementary Fig. 2f), caused similar Caspase-3-mediated apoptosis as GSNO (Supplementary Fig. 2g, h). The above results indicate that GSNO induces cell apoptosis in lung cancer cells through NO production.

\section{GSNO induces lung cancer cell apoptosis via Prdx2 nitrosylation}

GSNO exerts its biological function via activating classical sGC/cGMP-dependent pathway or nitrosylating certain proteins. To investigate the potential mechanism of cell apoptosis induced by GSNO, sGC inhibitor $1 \mathrm{H}$ $[1,2,4]$ oxadiazolo[4, 3a]quinoxalin-1-one (ODQ) or nitrosylation scavenger dithiothreitol (DTT) was applied to lung cancer cells. The results showed that ODQ failed to antagonize the effect of GSNO on A549 cells (Fig. 2a, Supplementary Fig. 3a), whereas DTT rescued the decreased cell viability induced by GSNO in A549 and NCI-H1299 cells (Fig. 2b, Supplementary Fig. 3b, c). Moreover, protein nitrosylation was markedly increased upon GSNO exposure and DTT attenuated the nitrosylation while ODQ did not (Fig. 2c, d). These results indicate that GSNO induces cell apoptosis through protein nitrosylation but not in a sGC/cGMP-dependent manner.

To find the potential proteins nitrosylated by GSNO, we focused on Prdxs, which regulate the oxidation status via critical Cys residues ${ }^{13}$. We downloaded publicly available data of 156 human samples (91 lung tumors tissues and 65 normal lung tissues) from GEO (GSE19188) ${ }^{20}$ to assess Prdxs mRNA expression. The results showed that Prdx2 


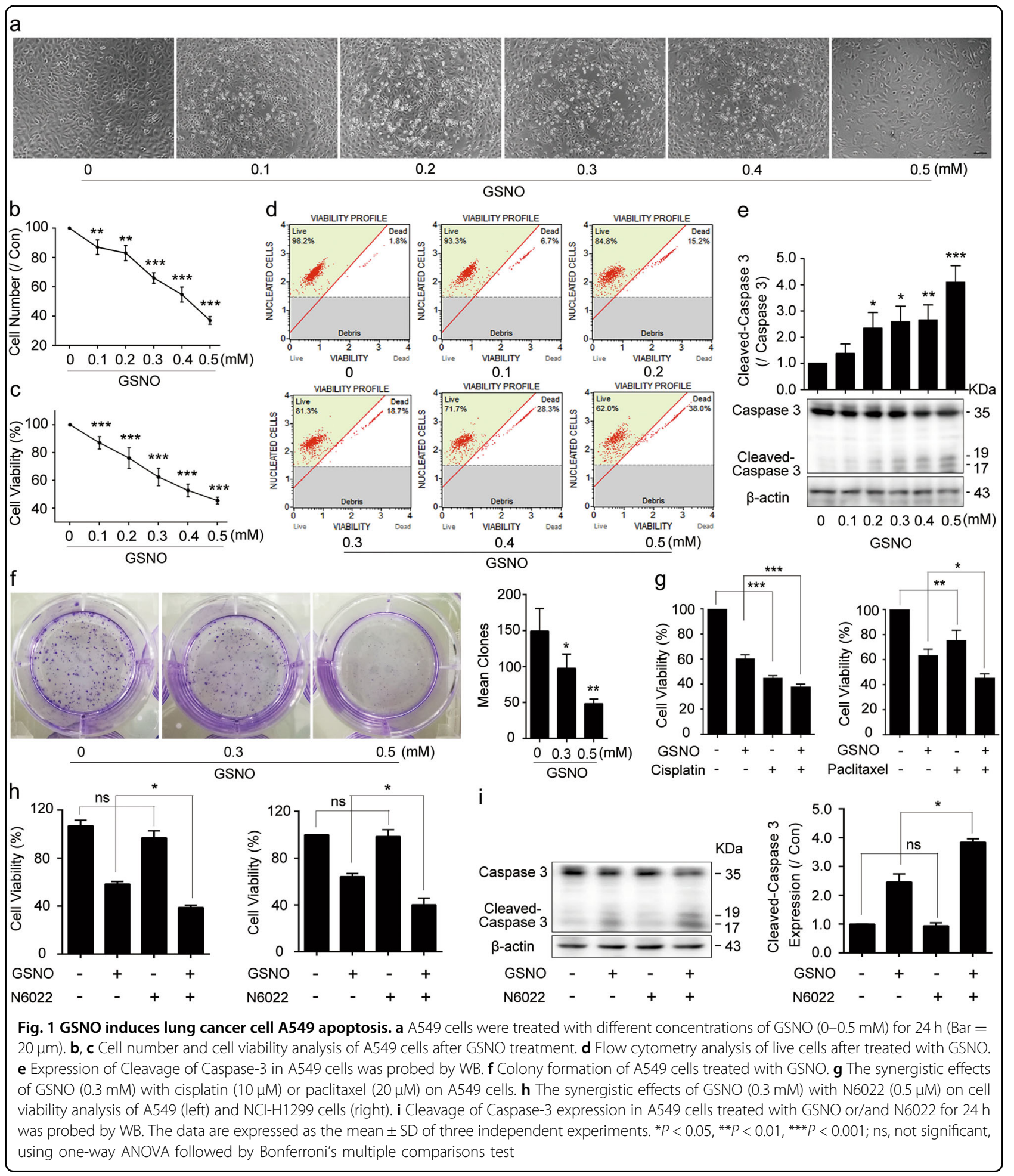

and Prdx4 were expressed higher in large cell lung carcinoma, lung adenocarcinoma, and squamous cell lung carcinoma compared with that in normal lung tissues (Fig. 2e, Supplementary Fig. 3d-h). Our results showed that the mRNA and protein levels of $\operatorname{Prdx} 2$ are higher in both A549 and H1299 cells than that in normal lung cells (WI38 and BEAS-2B; Supplementary Fig. 3i, k). However, Prdx4 mRNA level was only increased in NCI-H1299 cells but not in A549 cells (Supplementary Fig. 3j). The analysis of the association between clinicopathological features 

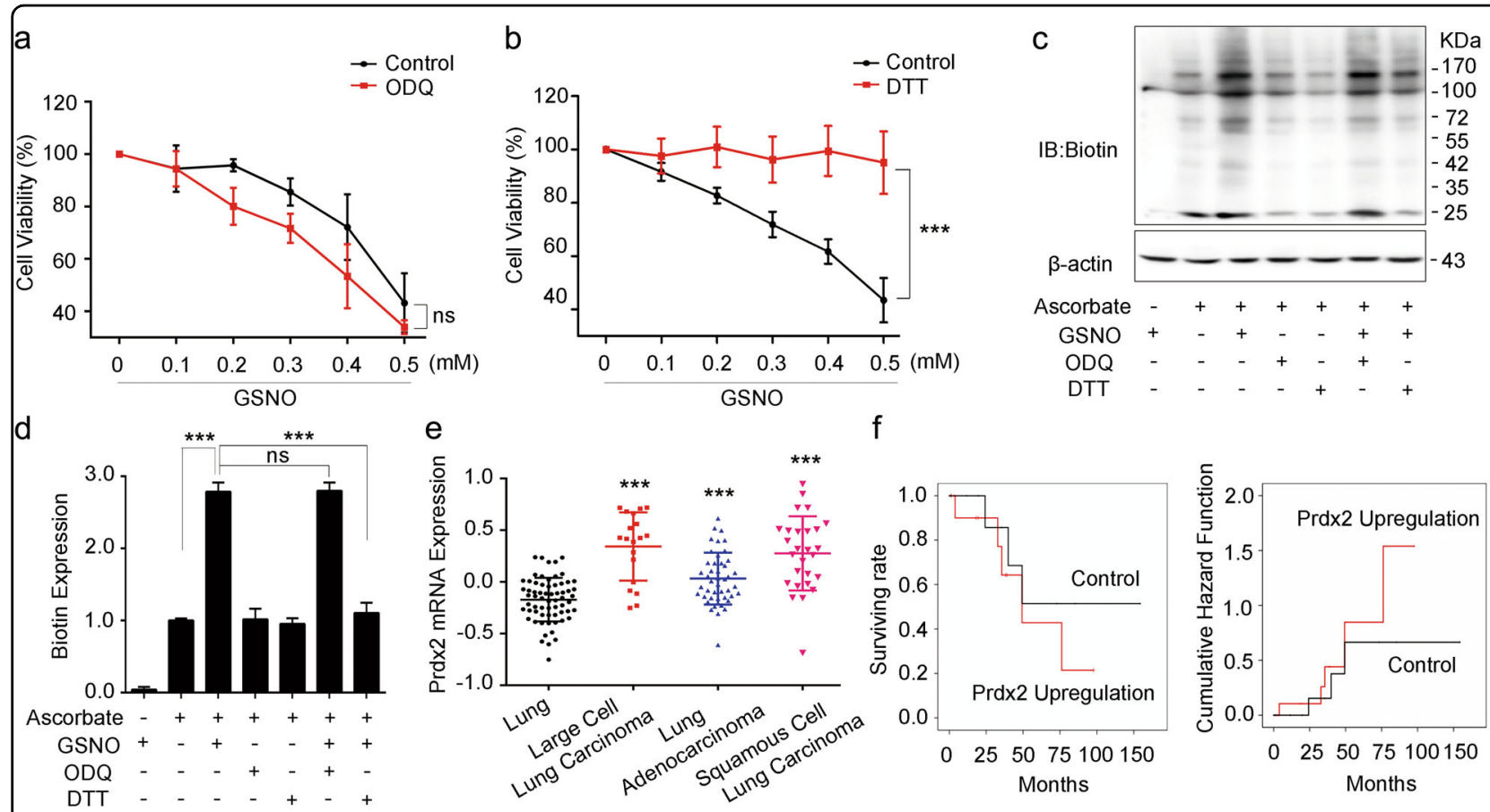

g
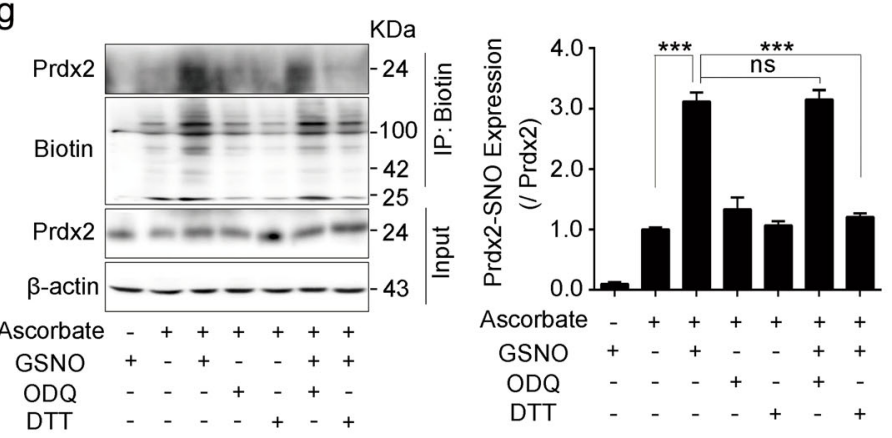

h i
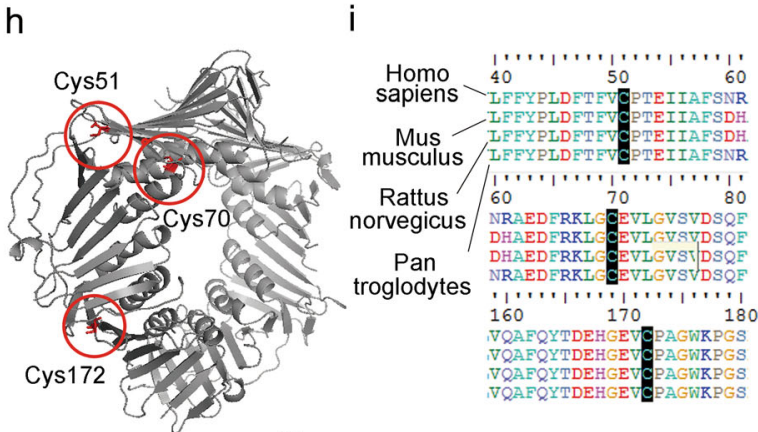
D

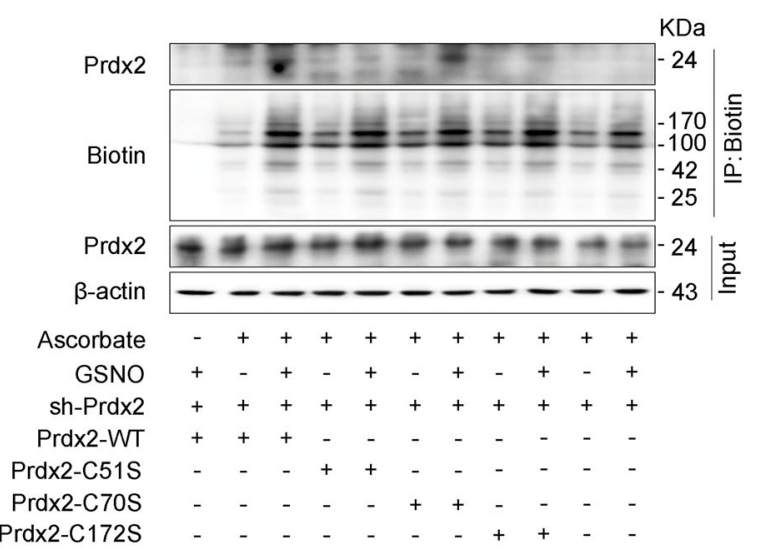

Prdx2-C51S-C172S

Prdx2-C51S-C172S

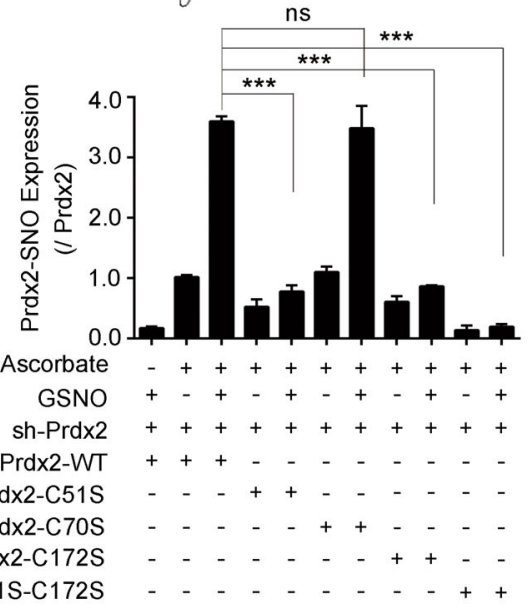

Fig. 2 (See legend on next page.) 
(see figure on previous page)

Fig. 2 GSNO promotes lung cancer cell apoptosis via Prdx2 nitrosylation. a Effect of GSNO on cell viability with or without ODQ $(25 \mu M)$ for $24 \mathrm{~h}$ (ns, not significant, using two-way ANOVA followed by Bonferroni's multiple comparisons test). b Effect of GSNO on cell viability with or without DTT $(0.5 \mathrm{mM})$ for $24 \mathrm{~h}\left({ }^{* * *} P<0.001\right.$, using two-way ANOVA followed by Bonferroni's multiple comparisons test). $\mathbf{c}$, $\mathbf{d}$ Detection of total protein nitrosylation by biotin-switch assay (*** $P<0.001$; ns, not significant, using one-way ANOVA followed by Bonferroni's multiple comparisons test). e The mRNA expression level of Prdx2 in different kinds of human lung cancer tissues and normal tissues ( ${ }^{* *} P<0.001$, using one-way ANOVA followed by Bonferroni's multiple comparisons test). $\mathbf{f}$ Kaplan-Meier survival curves for cumulative survival rate and cumulative hazard function of cancer patients according to expression level of Prdx2 mRNA. g Detection of Prdx2 nitrosylation by biotin-switch assay $(* * * P<0.001$; ns, not significant, using oneway ANOVA followed by Bonferroni's multiple comparisons test). $\mathbf{h}$ The 3D structure of Prdx2. The cysteine is shown in red. $\mathbf{i}$ Sequence alignment of Prdx2 in different species. $\mathbf{j}$ Expression of Prdx2 nitrosylation with GSNO treatment in different Prdx2 mutantions $(* * * P<0.001$; ns, not significant, using one-way ANOVA followed by Bonferroni's multiple comparisons test). The data are expressed as the mean \pm SD of three independent experiments

and high expression of Prdx2 showed that high expression of Prdx2 was significantly correlated with a poorer disease-free survival rate and a higher cumulative hazard function (Fig. 2f). Combined with the finding that GSNO could nitrosylate Prdx2 in mouse embryonic stem cells ${ }^{18}$, we hypothesized Prdx2 nitrosylation might be involved in the process of lung cancer cell apoptosis induced by GSNO. To validate this, we examined Prdx2 expression and its nitrosylation in lung cancer cells after GSNO treatment. The results showed that GSNO treatment did not affect the expression of $\operatorname{Prdx} 2$, but significantly increased its nitrosylation, which could be reversed by DTT but not by ODQ (Fig. 2g, Supplementary Fig. 3l). Saville-Griess assay also confirmed that GSNO treatment markedly increased the nitrosylation of both total cellular proteins and Prdx2 (Supplementary Fig. 3m). We further overexpressed Prdx2 in A549 cells and found it could rescue the GSNO-induced cell apoptosis (Supplementary Fig. 3n). Prdx2 contains three cysteine residues (Cys51, Cys70, and Cys172), which are highly conserved within species (Fig. 2h, i). We mutated these Cys sites to Ser separately. After silencing the endogenous Prdx2 by short hairpin RNA (shRNA) strategy, we re-expressed Prdx2 with different mutant forms in A549 cells. Our results showed that the mutation of Cys51 or Cys172, but not Cys70, markedly decreased the nitrosylation level of Prdx2 induced by GSNO (Fig. 2j), which was consistent with previous report that Cys51 and Cys172 were the predominant targets for $S$-nitrosylation on $\operatorname{Prdx} 2^{21}$.

\section{GSNO nitrosylates $\mathrm{Prdx2}$ and causes intracellular $\mathrm{H}_{2} \mathrm{O}_{2}$ accumulation}

Prdx2 catalytic cycle is related to $\mathrm{H}_{2} \mathrm{O}_{2}$ metabolism ${ }^{22}$. Cys51 of Prdx2 reacts with $\mathrm{H}_{2} \mathrm{O}_{2}$, then with the resolving Cys172 on the second subunit of the dimer to form disulfide bonds ${ }^{23}$ (Fig. 3a). Therefore, the nitrosylation of Prdx2 at Cys51 and Cys172 sites induced by GSNO might inhibit its catalytic cycle, subsequently resulting in $\mathrm{H}_{2} \mathrm{O}_{2}$ accumulation (Fig. 3b). We tested the Prdx2 monomer/ dimer ratio and found that GSNO significantly decreased dimer formation (Fig. 3c, d). Consistent with this finding,
GSNO increased intracellular $\mathrm{H}_{2} \mathrm{O}_{2}$ accumulation in A549 and NCI-H1299 cells (Fig. 3e, Supplementary Fig. 4a), which could be effectively eliminated by DTT (Fig. 3f). We further overexpressed Prdx2 in A549 cells and found it could reduce $\mathrm{H}_{2} \mathrm{O}_{2}$ accumulation induced by GSNO (Fig. 3g). To mimic the accumulation of $\mathrm{H}_{2} \mathrm{O}_{2}$, $\mathrm{H}_{2} \mathrm{O}_{2}$ was added to the cells. It increased the death of A549 and NCI-H1299 cells (Fig. 3h, i, Supplementary Fig. $4 \mathrm{~b}-\mathrm{h}$ ), which is similar to the effect of GSNO. Besides, the apoptosis caused by GSNO was reduced by adding ROS scavenger $N$-acetyl-L-cysteine (NAC, Fig. 3j, k). The above results indicated that GSNO could nitrosylate Prdx2 and inhibit its catalytic cycle, subsequently resulting in intracellular $\mathrm{H}_{2} \mathrm{O}_{2}$ accumulation and inducing lung cancer cell death.

\section{GSNO induces cell death via activating AMPK}

AMPK is a key energetic sensor and regulator of cellular metabolism that can be activated by the elevation of intracellular $\mathrm{H}_{2} \mathrm{O}_{2}$ levels ${ }^{24}$. We found that GSNO increased the phosphorylation of AMPK and ACC in a concentration-dependent manner in A549 and NCIH1299 cells (Fig. 4a, Supplementary Fig. 5a). In addition, N6022, SNAP, and LPS had synergistic effects with GSNO, respectively (Fig. 4b; Supplementary Fig. 5b, c). The activated AMPK induced by GSNO could be reversed by the application of DTT or overexpression of Prdx2 (Fig. 4c, d). Moreover, the addition of $\mathrm{H}_{2} \mathrm{O}_{2}$ to A549 and NCI-H1299 cells could mimic the effect of GSNO on the increase of AMPK phosphorylation (Fig. 4e; Supplementary Fig. 5d) and the activation of AMPK caused by GSNO was reduced by adding NAC (Fig. 4f). To confirm whether AMPK activation contributes to GSNO-induced lung cancer cell apoptosis, we used AMPK inhibitor dorsomorphin (Compound $\mathrm{C}$ ) and AMPK activator 5-aminoimidazole-4carboxamide 1- $\beta$-D-ribofuranoside (AICAR) to regulate the activity of AMPK. As expected, AICAR increased AMPK phosphorylation, whereas Compound $C$ attenuated AMPK phosphorylation caused by GSNO (Supplementary Fig. 5e, f). Moreover, Compound C but not AICAR attenuated the cell damage caused by GSNO in A549 and 


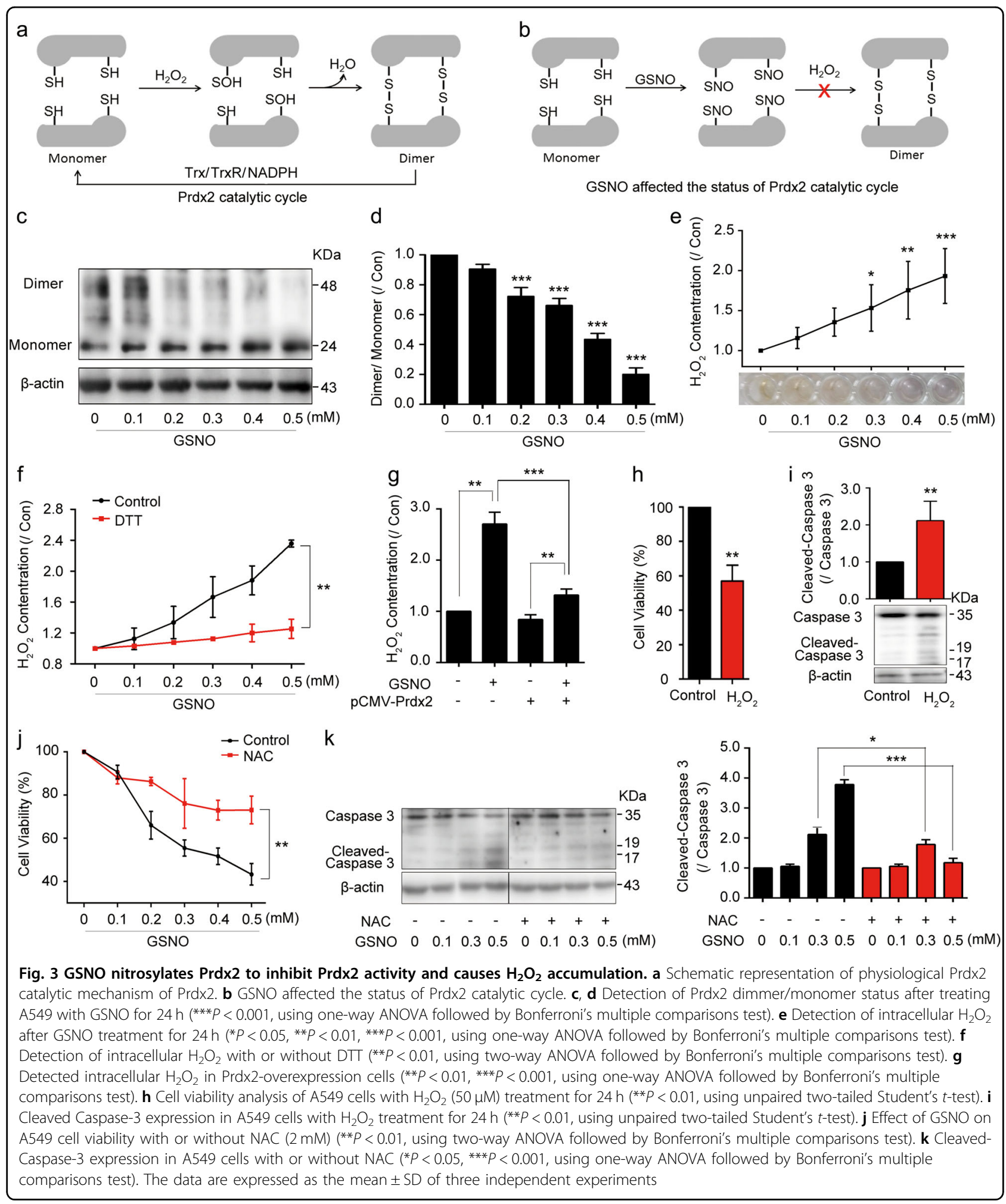

NCI-H1299 cells (Fig. 4g-i; Supplementary Fig. 5g). As Compound $\mathrm{C}$ has been reported exerting some side effects $^{24}$, we transfected alpha-subunit T172A-mutant AMPK into A549 cells. Our results showed that similar to
Compound $\mathrm{C}$, cell viability and apoptosis were rescued in T172A-mutant group (Fig. 4j, k, Supplementary Fig. 5j). These results demonstrate that GSNO induces cell death via activating AMPK. 


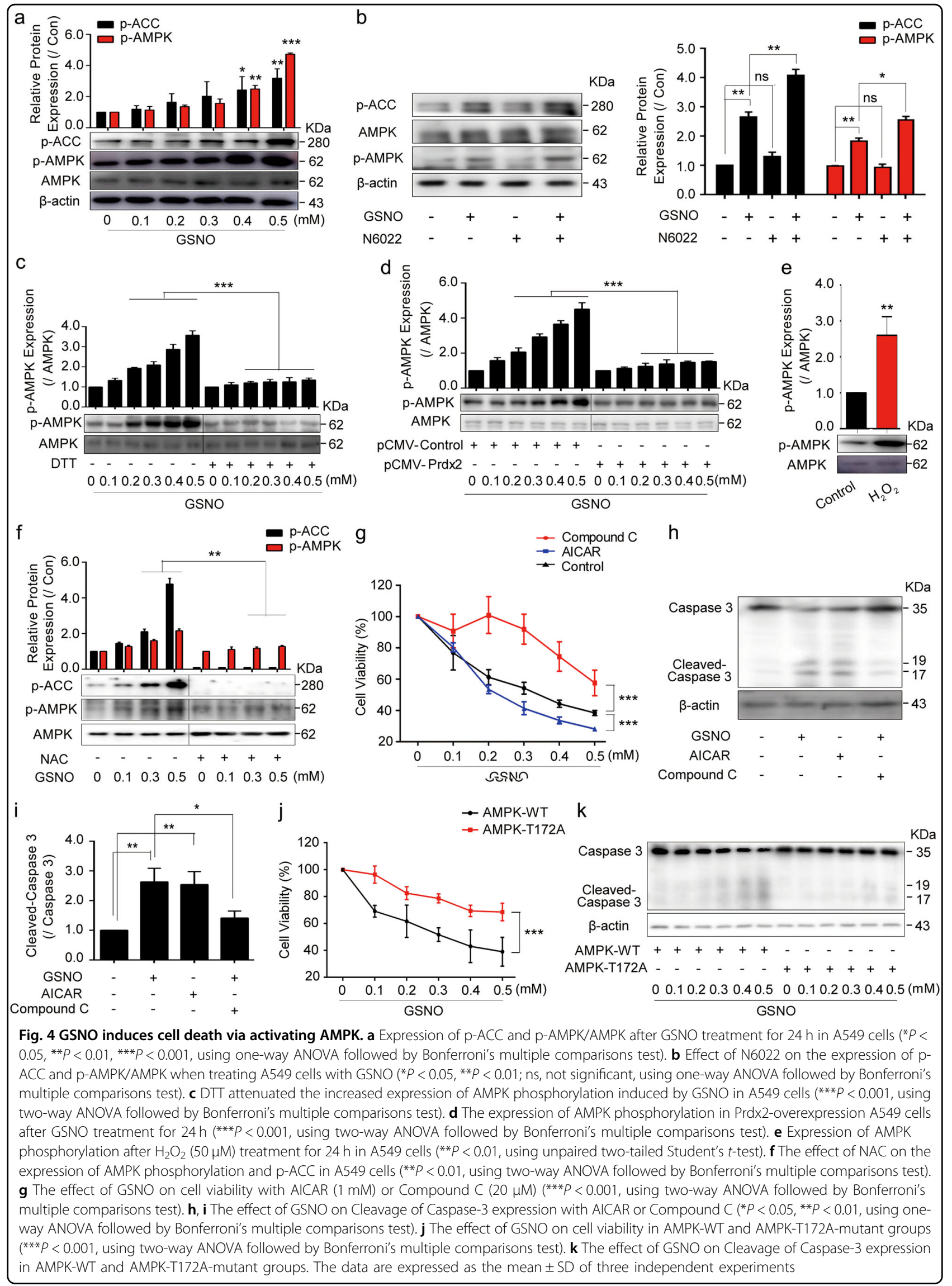




\section{AMPK phosphorylation inhibits SIRT1 activity}

SIRT1 is a cellular protective regulator that could be regulated by $\mathrm{AMPK}^{25}$. Our results showed GSNO significantly increased the formation of AMPK/SIRT1 complex (Fig. 5a, b), suggesting that the interaction between AMPK and SIRT1 might be affected by GSNO. We further detected the phosphorylation of SIRT1. AICAR and GSNO treatment resulted in a dramatic phosphorylation of SIRT1 at threonine (Fig. 5c, Supplementary Fig. 6a), which was abolished by Compound $\mathrm{C}$ (Fig. 5c, Supplementary Fig. 6a), knockdown of AMPK $\alpha 2$ (Fig. 5d), or T172A-mutant AMPK expression (Supplementary Fig. 6b). Furthermore, GSNO or AICAR treatment enhanced association of SIRT1 with AMPK (Fig. 5e). To understand the effect of SIRT1 phosphorylation mediated by AMPK, SIRT1 activity assays were carried out. We found it was decreased in A549 and NCI-H1299 cells after GSNO or AICAR treatment, which was abolished by Compound C (Fig. 5f, Supplementary Fig. 6c). As a potent activator of SIRT1, resveratrol attenuated the cell damage caused by GSNO; however, SIRT1 deacetylase inhibitor suramin could not further contribute to cell damage in A549 cells (Fig. 5g, Supplementary Fig. 6d). In addition, SIRT1 overexpression attenuated the cell damage caused by GSNO (Supplementary Fig. 6e, f). It was reported that AMPK activation induced SIRT1 phosphorylation at Thr344 site, which attenuated the affinity of SIRT1 for p53 and lead to a loss of SIRT1 deacetylase activity toward $\mathrm{p} 53^{26}$. To confirm whether GSNO-induced phosphorylation of SIRT1 is also at Thr344 site, non-phosphorylatable (T344A) mutants of SIRT1 was assessed for phosphorylation. The results revealed that treatment with GSNO significantly enhanced the wild-type SIRT1 threonine phosphorylation, but without any effect on the T344A-mutant SIRT1 (Fig. $5 \mathrm{~h}$ ), implying that AMPK activation induces the phosphorylation of SIRT1 at Thr344. Consistently, GSNO treatment inhibited the deacetylation activity of wild-type but not T344A-mutant SIRT1 (Fig. 5i). Moreover, adding $\mathrm{H}_{2} \mathrm{O}_{2}$ to A549 cells could mimic the effect of GSNO on the threonine phosphorylation of SIRT1, the association of SIRT1 and AMPK, and the deacetylation activity (Supplementary Fig. $6 \mathrm{~g}-\mathrm{j}$ ). It is reported that $S$-nitrosylation inhibits the activity of the protein deacetylase SIRT $1{ }^{27}$. Therefore, we test the $S$-nitrosylation of SIRT1. The results showed that even though SIRT1 had $S$ nitrosylation expression in control group, treatment with GSNO for $24 \mathrm{~h}$ did not increase its level of $S$-nitrosylation (Supplementary Fig. 6k), implying that the decrease of SIRT1 activity induced by GSNO treatment is independent of SIRT1 $S$-nitrosylation.

The above results indicate that local $\mathrm{H}_{2} \mathrm{O}_{2}$ accumulation induced by GSNO increases AMPK activity, which further inhibits SIRT1 deacetylase activity via phosphorylating SIRT1 at Thr344 site.

\section{GSNO induces A549 apoptosis via p53-dependent p21 induction}

It is reported that SIRT1 deacetylates p53 and inhibits p53-mediated cell death following DNA damage ${ }^{28}$. Consistently, we found GSNO impaired the interaction between SIRT1 and p53 (Fig. 6a), and increased the acetylation of p53 (Fig. 6b). p21, as a major target of p53 activity, which links DNA damage to cell cycle arrest, was activated by GSNO (Fig. 6b). N6022 and LPS had synergistic effects with GSNO on the activation of p53 and p21 (Fig. 6c, Supplementary Fig. 7a). These effects induced by GSNO could be reversed by application of DTT or overexpression of Prdx2 (Fig. 6d, e, Supplementary Fig. 7b, c). Moreover, adding $\mathrm{H}_{2} \mathrm{O}_{2}$ to A549 cells could mimic the effect of GSNO on the p53 acetylation and the expression of p21 (Fig. 6f). In addition, GSNO or AICAR treatment increased p53 acetylation and the expression of p21, which was abolished by Compound C (Fig. 6g). These results suggest that GSNO decreases the deacetylase activity of SIRT1 toward p53 and increases p53 acetylation. Acetylated p53 increases the expression of p21 and further promotes apoptosis in A549 cells (Fig. 6h).

\section{GSNO induces $\mathrm{H} 1299$ apoptosis via FOXO1 activation}

Although the above results showed that GSNO induced A549 cell apoptosis via p53 pathway, it raised another question why p53-null NCI-H1299 cells were killed by GSNO. It was reported that SIRT1 regulates cellular protective and apoptotic processes by deacetylating some vital proteins, including $\mathrm{p} 53, \mathrm{Ku} 70$, phosphatase and tensin homolog (PTEN), and FOXO transcription factors $^{29,30}$. Interestingly, we found GSNO decreased the interaction between SIRT1 and FOXO1 in NCl-H1299 cells (Fig. 7a, b), and the acetylation level of FOXO1 was significantly increased (Fig. 7c). Similarly, GSNO treatment also abrogated the binding of SIRT1 to PTEN (Supplementary Fig. 8a, b) and elevated the acetylation level of PTEN (Supplementary Fig. 8c). Experimental evidence indicates that the tumor suppressor activity of PTEN mostly relies on its counteracting activity on the phosphatidylinositol 3-kinase (PI3K)/protein kinase B (AKT) survival pathway, favoring apoptosis and/or cell cycle arrest $^{31}$. The result showed that the phosphorylation of AKT decreased after GSNO treatment (Supplementary Fig. 8d). FOXO1 is a well-known target of AKT and the phosphorylation of FOXO1 by AKT causes FOXO1 nuclear exclusion and inactivation ${ }^{32}$. Consistently, we found that GSNO treatment increased the expression of nuclear FOXO1 (Fig. 7d). These results indicate that GSNO increased PTEN acetylation, inhibited AKT 


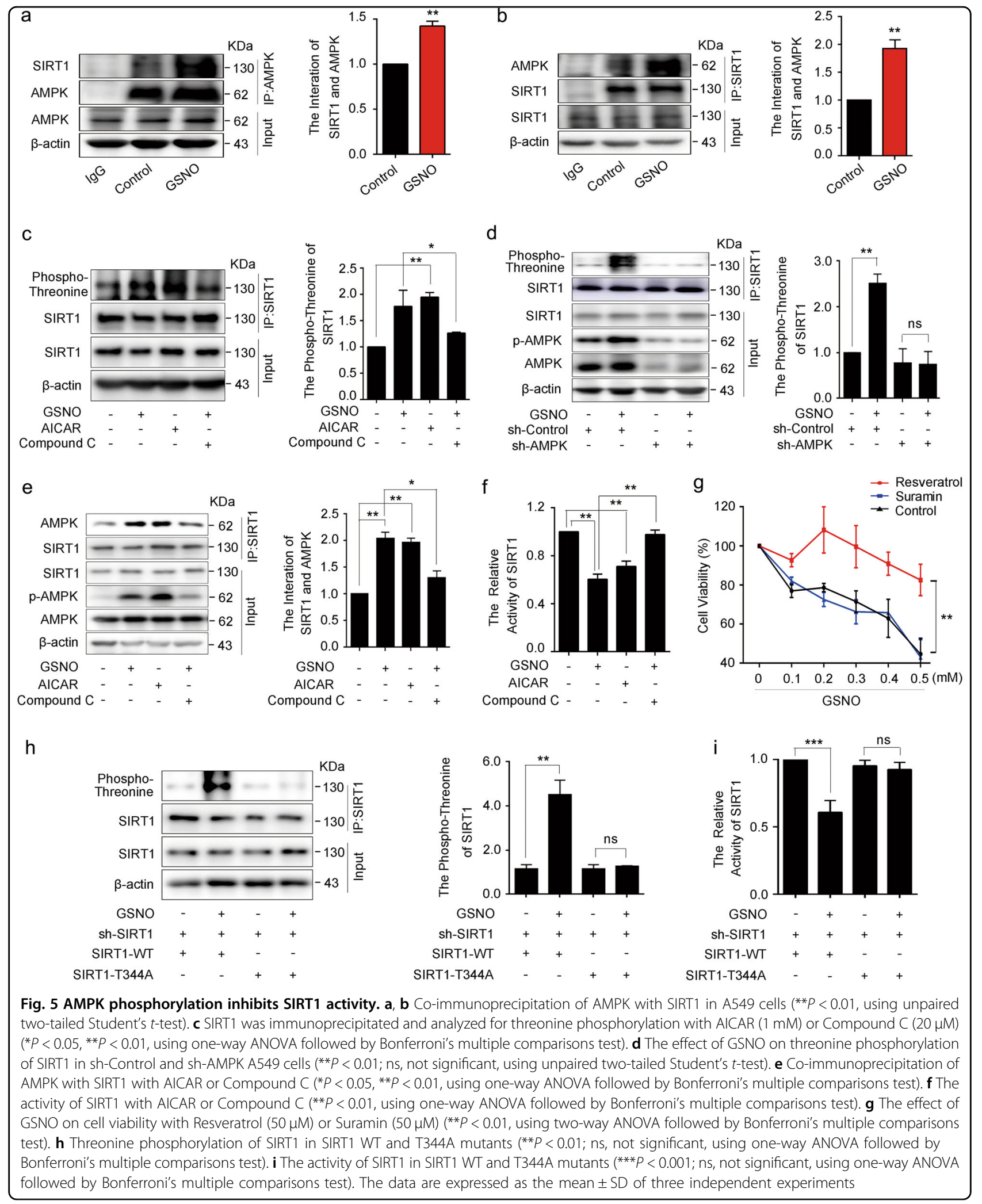




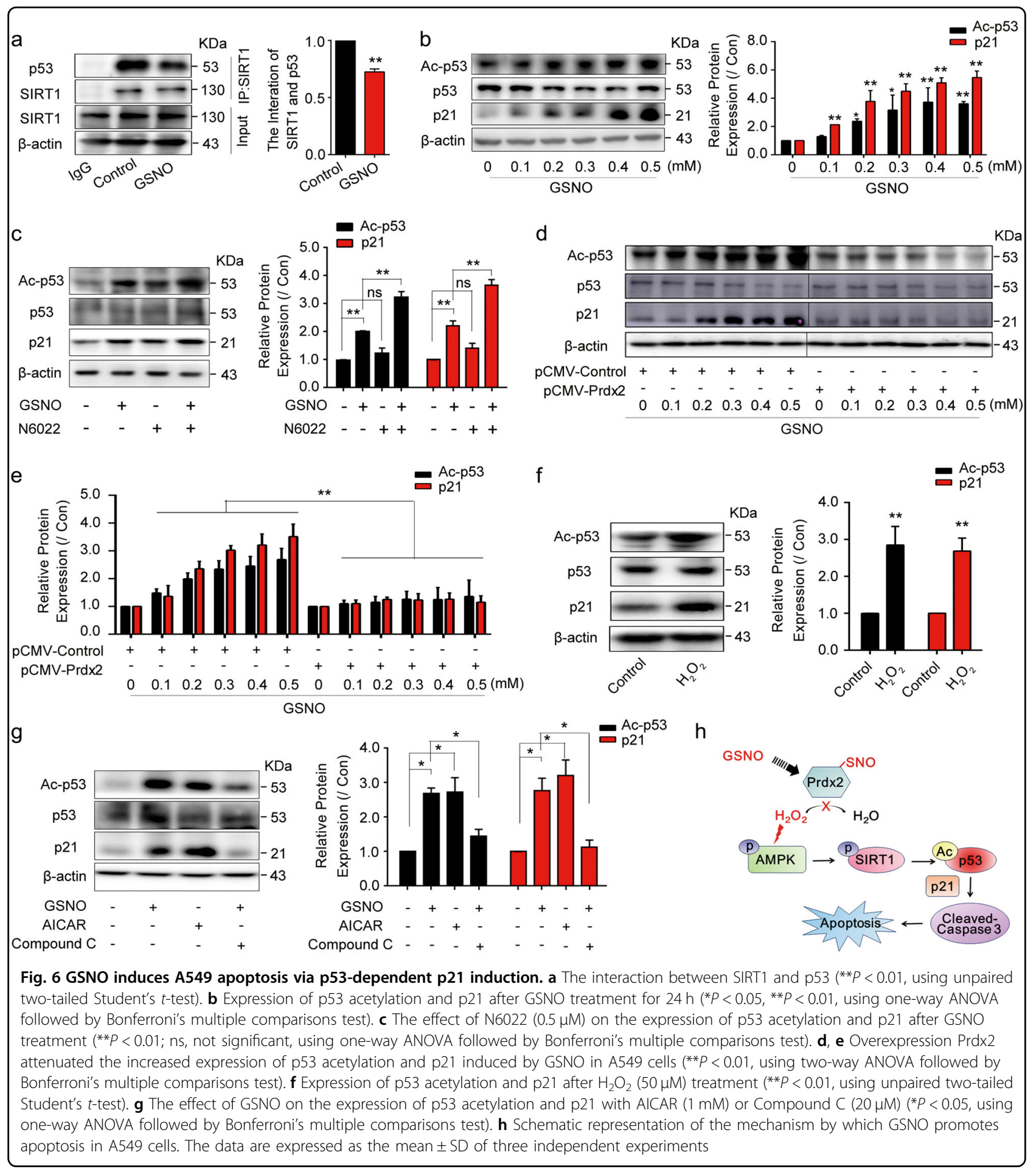

phosphorylation, and promoted FOXO1 nuclear translocation in p53-null NCI-H1299 cells. In line with the accumulation of FOXO1 in nuclear, the expression of its target genes Bim and Puma was significantly increased (Fig. 7e). However, in A549 cells, the acetylation of FOXO1 and PTEN was not obviously increased after
GSNO treatment (Supplementary Fig. 9a-d). We suspected that GSNO induced cell apoptosis mainly via p53 in A549 cells. In NCI-H1299 cells, inhibiting FOXO1 or PTEN by adding AS1842856 or VO-Ohpic trihydrate rescued decreased cell viability caused by GSNO (Supplementary Fig. 9e, f). However, in A549 cells, p53 


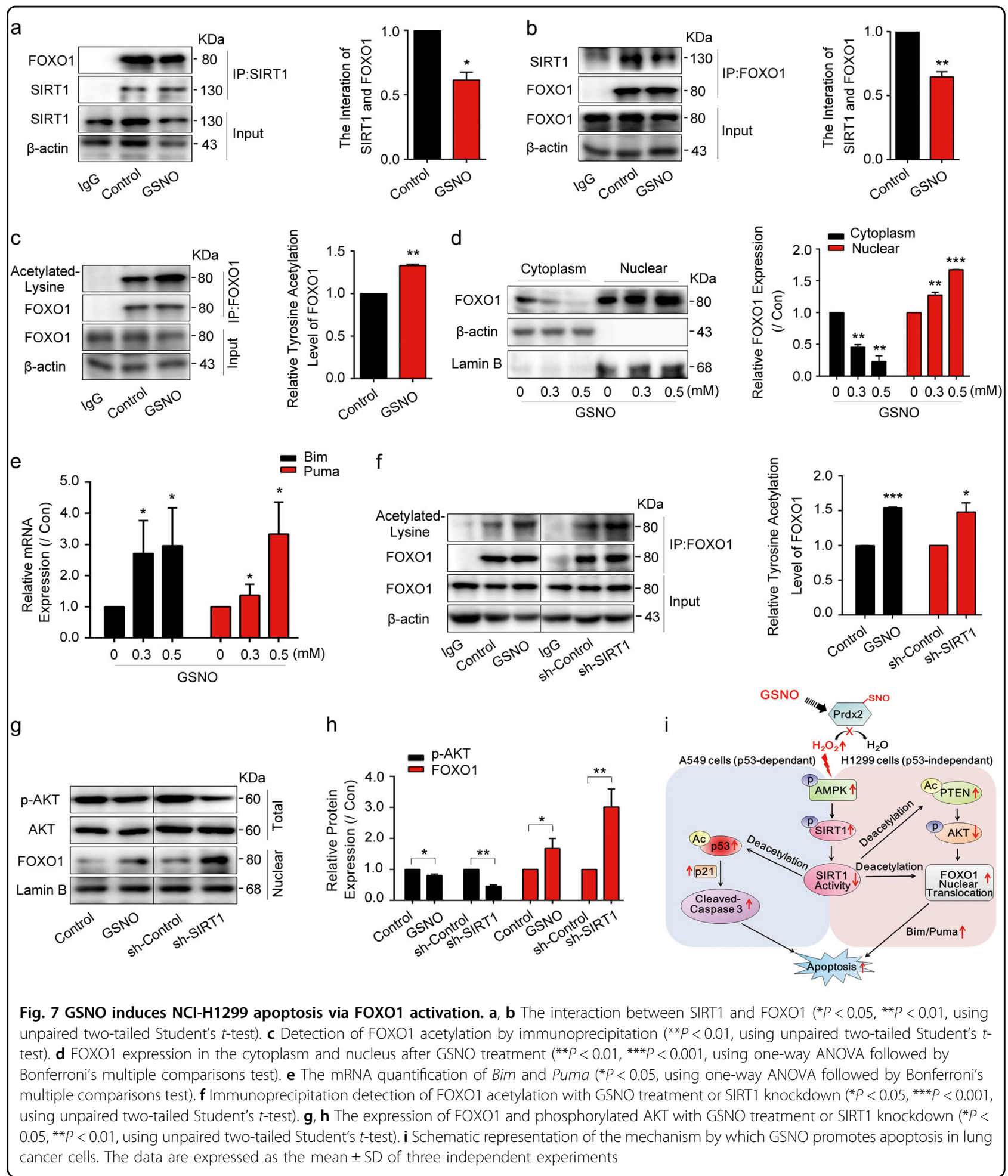

inhibitor Pifithrin- $\alpha$, but not FOXO1 inhibitor AS1842856, could rescue GSNO-induced decrease of cell viability (Supplementary Fig. 9g, h). To confirm whether SIRT1 inactivation contributed to FOXO1 nuclear translocation, sh-SIRT1 was used in NCI-H1299 cells.
The results showed silence of SIRT1 promoted the acetylation of FOXO1 and PTEN (Fig. 7f, Supplementary Fig. $8 \mathrm{e}$ ), as well as FOXO1 nuclear translocation (Fig. $7 \mathrm{~g}, \mathrm{~h}$ ). We also focused on the possibility whether PTEN can be inhibited by nitrosylation. However, we did not observe 
any nitrosylation of PTEN when treated with GSNO (Supplementary Fig. 8f). Collectively, these data demonstrate GSNO induces the apoptosis in NCI-H1299 cells via FOXO1 activation (Fig. 7i).

\section{Discussion}

Previous studies indicated that GSNO can induce apoptosis in various cells ${ }^{11,33,34}$ by the activation of many signaling pathways, including $\mathrm{p} 53$, nuclear factor $-\mathrm{kB}$, and STAT3 pathways ${ }^{35}$. However, whether there are other pathways involved in it and the details of the signaling pathway still remain unclear. In this study, we reported that GSNO induced lung cancer cell apoptosis via Prdx2 and AMPK pathway.

Prdx2 has been found to be elevated in several human cancer tissues, including colorectal cancer ${ }^{36}$, and it affects diverse cellular processes involving cell proliferation and apoptosis via Wnt/ $\beta$-catenin, transforming growth factor- $\beta 1$, and PI3K/AKT ${ }^{14,37,38}$. Thus, inhibition of Prdx2 expression or activity is expected to be a new strategy for treating tumors. For example, Prdx2 knockdown inhibited colorectal cancer cell growth, which had high Prdx2 mRNA expression. However, Prdx2 mRNA level is low, whereas the protein expression level is high in the lung. Therefore, to regulate Prdx2 activity through posttranslational modification is an alternative way to inhibit lung cancer cell growth. Our findings suggest that it is possible to inhibit Prdx2 enzyme activity by nitrosylation.

There is a report that GSNO decreased the activation of AMPK, which was activated in cerebral ischemia reperfusion (IR) brains ${ }^{39}$. This seems to be opposite with our results and we guess there are two possible reasons. First, the state of AMPK is different: the AMPK has already been over activated in IR brains. Second, GSNO has different roles in oxidation system. In our lung cancer cellular models, it contributes $\mathrm{H}_{2} \mathrm{O}_{2}$ accumulation and promotes oxidative effects, whereas GSNO can also protect against oxidative stress in the endothelium, myocardium, brain tissues, and other cells ${ }^{10}$. The above two differences may explain the opposite effects of GSNO on AMPK.

Most importantly, we further revealed why AMPK activation induced by GSNO caused cell apoptosis. As previously reported, AMPK is involved in diverse protein phosphorylation ${ }^{40}$. For example, AMPK induced phosphorylation of SIRT1 at Thr344. It was reported that SIRT1 was phosphorylated and inactivated by AMPK at Thr344, promoting p53 acetylation and apoptosis of HCC cells $^{26}$. In this study, GSNO significantly increased AMPK/SIRT1 interaction. Moreover, treatment with GSNO significantly enhanced the threonine phosphorylation of wild-type SIRT1 rather than T344A-mutant SIRT1, implying that AMPK activation induces the phosphorylation of SIRT1 at Thr344.
In summary, our study demonstrates that GSNO could induce lung cancer cell apoptosis via nitrosylating Prdx2 to induce $\mathrm{H}_{2} \mathrm{O}_{2}$ accumulation, subsequently increasing AMPK phosphorylation and further inhibiting the activity of SIRT1. SIRT1 inactivation induced apoptosis via p53 acetylation or FOXO1 activation in lung cancer cells with different p53 status. This discovery implies that GSNO could be a candidate therapeutic compound applicable to a wide range of human cancers regardless of their p53 status. Moreover, clinical data show that high expression of Prdx2 was closely correlated with unfavorable prognosis. Collectively, Prdx2 may be regarded as a potential target for clinical treatment of non-small cell lung cancer.

\section{Materials and methods \\ Reagents and antibodies}

Cell culture reagents were purchased from GE and fetal bovine serum (FBS) was purchased from PANBiotech; DTT was purchased from Millipore (Massachusetts, USA); Compound C, AICAR, Resveratrol, Suramin, SNAP, and ODQ were purchased from SigmaAldrich; N6022, Pifithrin- $\alpha$, VO-Ohpic trihydrate, AS1842856, and MK 2206 were from MCE. Hydrogen peroxide $\left(\mathrm{H}_{2} \mathrm{O}_{2}\right)$ was from Sinopharm Chemical Reagent; 3-(4,5-dimethyl-2-thiazolyl)-2,5-diphenyl-2$\mathrm{H}$-tetrazolium bromide (MTT) was purchased from Sangon Biotech; Lipofectamine ${ }^{\circledR} 3000$ and Attractene were from Thermo Fisher Scientific and Qiagen, respectively. Fluor-de-Lys SIRT1 fluorometric drug discovery assay kit was from Enzo Life Sciences; Hydrogen Peroxide Assay Kit, Nitric Oxide Assay Kit, RIPA lysis buffer, Bicinchoninic Acid assay Kit, and Nuclear and Cytoplasmic Protein Extraction Kit were from Beyotime; Super ECL Prime was from US Everbright ${ }^{\circledR}$ Inc. The mRNA extraction kit was from Bioteke. Protein A Magnetic Beads and the Muse Count \& Viability Assay Kit were purchased from Millipore. AntiFlag M2 Magnetic Beads was from Sigma-Aldrich. Antibodies for phospho- and total-AMPK, acetyl- and total-p53, SIRT1, Cleaved- and total-Caspase-3, FOXO1, PTEN, $\beta$-actin, and acetylated-Lysine were from Cell Signaling Technology; antibodies for P21 was from Abcam; antibodies for Prdx2 was from Santa Cruz Biotechnology.

\section{GSNO synthesis}

GSNO was synthesized as described previously ${ }^{41}$. In brief, the following reagents were prepared: glutathione (GSH) $400 \mathrm{mM}, \mathrm{NaNO}_{2} 400 \mathrm{mM}, \mathrm{HCl} 200 \mathrm{mM}$, and $40 \%$ $\mathrm{NaOH}$. $\mathrm{HCl}(2 \mathrm{ml})$ was added to $\mathrm{GSH}(4 \mathrm{ml})$ for acidification and then $\mathrm{NaNO}_{2}(4 \mathrm{ml})$ was added for $20 \mathrm{~min}$ in ice bath. $\mathrm{NaOH}(40 \%)$ was added and $\mathrm{pH}$ adjusted to around 7.0 and characterized by UV spectroscopy. 


\section{Cell culture treatment and transfection}

NCI-H1299, A549, WI38, BEAS-2B, and 293T were obtained from the American Type Culture Collection (Manassas, VA, USA). Cell lines were grown in RPMI 1640 medium or Dulbecco's modified Eagle's medium supplemented with $10 \% \mathrm{FBS}$. Cell lines were grown at $37^{\circ} \mathrm{C}$ in a humidified atmosphere containing $5 \% \mathrm{CO}_{2}$ and 95\% air. Cells were treated with different doses of GSNO for $24 \mathrm{~h}$. Cells were transfected with different vectors using Attractene or Lipofectamine ${ }^{\circledR} 3000$ according to the manufacturer's protocol. The overexpression efficiency was shown in Supplementary Fig. 10a-d.

\section{Cell survival assay}

The cells in 96-well culture plates were treated with different doses of GSNO for $24 \mathrm{~h}$. MTT solution in media was added to each well at a final concentration of $1 \mathrm{mg} /$ $\mathrm{mL}$. The plate was incubated for $4 \mathrm{~h}$ at $37^{\circ} \mathrm{C}$. The medium was discarded, formazan crystals were dissolved in dimethyl sulfoxide, and the absorbance was measured at $490 \mathrm{~nm}$. Experiments were performed in triplicate.

\section{Colony-formation assays}

For colony-formation assays, A549 and NCI-H1299 cells were seeded in 6-well culture plates (400 cells/well) and grown for 10-14 days. Colonies were fixed with paraformaldehyde $(4.0 \% \mathrm{v} / \mathrm{v})$, stained with crystal violet $(0.5 \% \mathrm{w} / \mathrm{v})$, and photographed.

\section{Flow cytometry analysis}

Muse Count \& Viability reagent $(20 \mu \mathrm{l})$ and then cell suspension $(380 \mu \mathrm{l})$ were added to each tube. The tube was incubated for $5 \mathrm{~min}$ at room temperature and the cell count and viability were detected using Merck \& Millipore Muse Cell Analyzer.

\section{Biotin-switch assay}

Cells were lysed in appropriate amount of lysis buffer (50 mM NaCl, $25 \mathrm{mM}$ Hepes, $0.1 \mathrm{mM}$ EDTA, $0.1 \mathrm{mM}$ neocuproine, $1 \% \mathrm{NP}-40,0.5 \mathrm{mM}$ phenylmethylsulfonyl fluoride plus protease inhibitors, $\mathrm{pH}$ 7.4), unmodified protein - $\mathrm{SH}$ groups were blocked with $10 \%$ methylmethanethiosulfonate for $30 \mathrm{~min}$ at $50^{\circ} \mathrm{C}$. Protein extracts were precipitated with cold acetone $\left(\right.$ at $-20^{\circ} \mathrm{C}$ ) and resuspended in solubilizing buffer (100 mM Hepes, $1 \mathrm{mM}$ EDTA, $0.1 \mathrm{mM}$ neocuproine, $1 \%$ SDS). Ascorbic acid was added to remove nitrosyl groups. The biotinylated proteins were biotinylated with biotin-HPDP and then detected by immunoblotting with biotin antibody or pulled down with streptavidin magnetic beads.

\section{-SNO detection}

Saville-Griess assay was used to detect $-\mathrm{SNO}$ of total protein and $\operatorname{Prdx} 2$ as previously reported ${ }^{42}$. For total protein, in brief, untreated and GSNO-treated cell lysates were prepared by precipitation in iced acetone followed by dissolution in incubation buffer. Mercury displacement of NO from SNO proteins was elicited by $10 \mathrm{~min}$ of incubation with $100 \mu \mathrm{M} \mathrm{HgCl}_{2}$. Nitrite levels were determined colorimetrically after reaction with $100 \mu \mathrm{l}$ of working Griess reagent (1:1 mixture of $1 \%$ sulfanilamide and $\quad 0.1 \% \quad N$-(1-naphthyl)-ethylenediamine dihydrochloride) and quantified in a spectrophotometer at A540 relative to sodium nitrite standards. For Prdx2, A549 cells were transfected with pCMV-Prdx2 and then purified Prdx2 protein using anti-Flag M2 magnetic beads. SNO quantification of Prdx2 was detected in the same way.

\section{$\mathrm{H}_{2} \mathrm{O}_{2}$ content detection}

Analyses were performed using hydrogen peroxide assay kit. In brief, after treatment, cells were collected and the lysis buffer solution supplied with the kit was added at a ratio of $150 \mu \mathrm{l}$ per $1 \times 10^{6}$ cells. Then the cells were centrifuged at $10,000 \times g$ for $15 \mathrm{~min}$ at $4{ }^{\circ} \mathrm{C}$ and the supernatants were collected. Test tubes containing $50 \mu \mathrm{l}$ supernatants and $100 \mu \mathrm{l}$ test solutions were placed at room temperature for $30 \mathrm{~min}$ and measured immediately with a spectrophotometer at a wavelength of $560 \mathrm{~nm}$. The concentration of $\mathrm{H}_{2} \mathrm{O}_{2}$ released was calculated from standard concentration curve with triplicate experiments.

\section{NO content detection}

Analyses were performed using NO assay kit according to the manufacturer's protocol. In brief, we used a commercial kit to quantify the level of NO according to the manufacturer's protocol. Cell and Tissue Lysis Buffer for Nitric Oxide Assay was used to lyse cells. Lysed cells were centrifuged at $10,000 \times g$ for $10 \mathrm{~min}$ to remove debris. Test tubes containing $50 \mu \mathrm{l}$ supernatants, $50 \mu \mathrm{l}$ Griess Reagent I, and $50 \mu \mathrm{l}$ Griess Reagent II were measured with a spectrophotometer at a wavelength of $540 \mathrm{~nm}$.

\section{Prdx2 dimer/monomer detection}

As reported previously ${ }^{43}$, after GSNO treatment for $24 \mathrm{~h}$, A549 cells were digested, centrifuged, and resuspended in $1 \mathrm{~mL}$ D-hank's containing $100 \mathrm{mM} \mathrm{N} N$-ethyl maleimide (NEM) to preserve the Prdx2 redox state. After $20 \mathrm{~min}$ incubation at $37^{\circ} \mathrm{C}$, cells were pelleted and lysed in $400 \mu \mathrm{l}$ nonreducing lysis buffer $(100 \mathrm{mM}$ Tris- $\mathrm{HCl}, \mathrm{pH}$ $6.8,10 \%(\mathrm{v} / \mathrm{v})$ glycerol, $2 \%(\mathrm{w} / \mathrm{v})$ SDS, $0.01 \%(\mathrm{w} / \mathrm{v})$ bromophenol blue) containing $100 \mathrm{mM}$ NEM and immediately frozen at $20^{\circ} \mathrm{C}$ for immunoblotting detection.

\section{Knockdown of SIRT1, AMPK, and Prdx2 using shRNA}

The pLKO.1-shRNA-SIRT1-lentiviral vector, pLKO.1shRNA-AMPK-lentiviral vector, and pLKO.1-shRNAPrdx2-lentiviral vector were constructed (pLKO.1, a 
lentiviral vector, Addgene), SIRT1 target sequence: 5'TGAGGAGGTCAACTTCATC-3'; AMPK $\alpha 2$ target sequence: $5^{\prime}$-GCCATAAAGTGGCAGTTAA-3'; Prdx2 target sequence: 5'-GGAAGTACGTGGTCCTCTT-3'. HEK293T cells were co-transfected with lentiviral vector, psPAX2 and pMD2G vectors for virus production. Stable cell lines were obtained by lentiviral infection and selection with puromycin $(1 \mu \mathrm{g} / \mathrm{ml})$ or hygromycin B $(200 \mu \mathrm{g} /$ $\mathrm{ml}$ ) for 2 weeks. The knockout efficiency was shown in Supplementary Fig. 10e.

\section{Co-immunoprecipitation}

Untreated and GSNO-treated cells were washed once with phosphate-buffered saline and $500 \mu \mathrm{L}$ NETN lysis buffer (20 mM Tris, pH 8.0, $100 \mathrm{mM} \mathrm{NaCl}, 1 \mathrm{mM}$ EDTA, $0.5 \% \mathrm{NP}-40$ ) lysed for $20 \mathrm{~min}$ on ice. Cell lysates were then centrifuged at 12,000 r.p.m., $4{ }^{\circ} \mathrm{C}$ for $10 \mathrm{~min}$. The soluble fraction was collected and then $50 \mu \mathrm{L}$ supernatant liquid was left as input; the rest of supernatant liquid was immunoprecipitated overnight with anti-SIRT1 or antiAMPK antibody at $4{ }^{\circ} \mathrm{C}$ and then with protein A magnetic beads for another $4 \mathrm{~h}$. After that, the protein A magnetic beads were washed three times with NETN buffer. The beads were then boiled for $10 \mathrm{~min}$ in 1\% SDS loading buffer for WB with the indicated antibodies.

\section{Measurement of SIRT1 activity}

SIRT1 enzymatic activities were measured in A549 and NCI-H1299 using the commercially available SIRT1 Fluorometric Kit according to the manufacturer's instructions.

\section{Real-time quantitative PCR}

Total RNA was extracted from A549 or NCI-H1299 cells by RNA extraction kit. Then, cDNA was synthesized using M-MLV Reverse Transcriptase (Takara) according to the manufacturer's instructions. Detection of mRNA levels was performed using a 7500 Real-Time PCR System (Applied Biosystems) and SYBR Green master mix (Roche).The forward and reverse primers were shown in Supplementary Table 1. Real-time quantitative PCR was performed in triplicate and the mRNA levels of target genes were normalized to glyceraldehyde 3-phosphate dehydrogenase.

\section{Western blotting}

Cells were homogenized in RIPA lysis buffer, followed with centrifugation (10,000 r.p.m., $10 \mathrm{~min}$ ). Total protein concentration in the supernatant was determined with Bicinchoninic Acid assay. Ten microliters of lysates was resolved by SDS-polyacrylamide gel electrophoresis, transferred onto polyvinylidene difluoride membrane, and probed for the specified antibody overnight at $4{ }^{\circ} \mathrm{C}$. Secondary antibodies, conjugated with horseradish peroxidase were incubated at room temperature for $1 \mathrm{~h}$. Proteins were visualized using ECL.

\section{Statistical analysis}

Data were expressed as mean values $\pm \mathrm{SD}$. The statistical and plotting software package GraphPad Prism 5.0 (GraphPad Software, America) was used to perform unpaired two-tailed Student's $t$-test, one-way analysis of variance (ANOVA), or two-way ANOVA followed by Bonferroni's multiple comparisons test. The data of Prdxs mRNA expression in tumor and normal tissue was obtained from GEO (GSE19188). The patient data for survival analysis was obtained from the Cancer Genome Atlas database via the cBioPortal for Cancer Genomics. The survival rate after surgery was calculated using the Kaplan-Meier method by SPSS 17.0 software (SPSS, Chicago, USA).

\section{Acknowledgements \\ This work is supported by National Key R\&D Program of China (2018YFD0901103), the National Natural Science Foundation of China (U1606403, U1706210, 81871868 and 31870795), Qingdao Application Basic Research Project (18-2-2-46-jch), the Scientific and Technological Innovation Project financially supported by Qingdao National Laboratory for Marine Science and Technology (No. 2015ASKJ02), and also funded by Open Research Fund Program of Shandong Provincial Key Laboratory of Glycoscience \& Glycotechnology (Ocean University of China).}

\section{Author details \\ ${ }^{1}$ Key Laboratory of Marine Drugs, Ministry of Education, School of Medicine and Pharmacy, Ocean University of China, 5 Yushan Road, Qingdao 266003, China. ${ }^{2}$ Laboratory for Marine Drugs and Bioproducts of Qingdao National Laboratory for Marine Science and Technology, Qingdao 266200, China. ${ }^{3}$ Key Laboratory of Glycoscience \& Glycotechnology of Shandong Province, \\ Qingdao 266003, China}

\section{Author contributions}

$Y . Z$. designed, performed the experiments, analysis, and interpretation of data. C.S., G.X., H.S., L.T. and Y.Y. assisted with the experiments and data analysis. W.Y. and Y.G. supervised the project. Y.Z. wrote the original draft. Y.Z. and Y.G. discussed, reviewed, and edited the manuscript.

Competing interests

The authors declare that they have no conflicts of interest.

\section{Publisher's note}

Springer Nature remains neutral with regard to jurisdictional claims in published maps and institutional affiliations.

Supplementary Information accompanies this paper at (https://doi.org/ 10.1038/s41419-019-1561-x).

Received: 24 August 2018 Revised: 25 February 2019 Accepted: 29 March 2019

Published online: 15 April 2019

References

1. Rothschild, S. I. [Advanced and metastatic lung cancer - what is new in the diagnosis and therapy?]. Praxis (Bern 1994) 104, 745-750 (2015).

2. Wood, S. L., Pernemalm, M., Crosbie, P. A. \& Whetton, A. D. Molecular histology of lung cancer: from targets to treatments. Cancer Treat. Rev. 41, 361-375 (2015). 
3. Plenchette, S., Romagny, S., Laurens, V. \& Bettaieb, A. S-Nitrosylation in TNF superfamily signaling pathway: implication in cancer. Redox Biol. 6, 507-515 (2015).

4. Foster, M. W., Hess, D. T. \& Stamler, J. S. Protein S-nitrosylation in health and disease: a current perspective. Trends Mol. Med. 15, 391-404 (2009).

5. Gaston, B., Singel, D., Doctor, A. \& Stamler, J. S. S-nitrosothiol signaling in respiratory biology. Am. J. Respir. Crit. Care Med. 173, 1186-1193 (2006).

6. Wang, Z. Protein S-nitrosylation and cancer. Cancer Lett. 320, 123-129 (2012)

7. Iwakiri, Y. \& Kim, M. Y. Nitric oxide in liver diseases. Trends Pharmacol. Sci. 36, 524-536 (2015).

8. Corpas, F. J., Alche, J. D. \& Barroso, J. B. Current overview of Snitrosoglutathione (GSNO) in higher plants. Front. Plant Sci. 4, 126 (2013).

9. Gaston, B. M., Carver, J., Doctor, A. \& Palmer, L. A. S-nitrosylation signaling in cell biology. Mol. Inter. 3, 253-263 (2003).

10. Olivier, P. et al. Nitric oxide plays a key role in myelination in the developing brain. J. Neuropathol. Exp. Neurol. 69, 828-837 (2010).

11. Singh, I., Kim, J., Singh, A. K., Sharma, A. K. \& Won, J. S. STAT3 regulation by Snitrosylation: implication in cancer. Redox Biol 5, 416-417 (2015).

12. Fatma, N., Kubo, E., Sharma, P., Beier, D. R. \& Singh, D. P. Impaired homeostasis and phenotypic abnormalities in Prdx6-/-mice lens epithelial cells by reactive oxygen species: increased expression and activation of TGFbeta. Cell Death Differ. 12, 734-750 (2005).

13. Park, M. H., Jo, M., Kim, Y. R., Lee, C. K. \& Hong, J. T. Roles of peroxiredoxins in cancer, neurodegenerative diseases and inflammatory diseases. Pharmacol. Ther. 163, 1-23 (2016).

14. Lu, W. et al. Peroxiredoxin 2 knockdown by RNA interference inhibits the growth of colorectal cancer cells by downregulating Wnt/beta-catenin signaling. Cancer Lett. 343, 190-199 (2014).

15. Poillet-Perez, L., Despouy, G., Delage-Mourroux, R. \& Boyer-Guittaut, M. Interplay between ROS and autophagy in cancer cells, from tumor initiation to cancer therapy. Redox Biol. 4, 184-192 (2015).

16. LV, Z. et al. Disruption of the c-Myc/miR-200b-3p/PRDX2 regulatory loop enhances tumor metastasis and chemotherapeutic resistance in colorectal cancer. J. Transl. Med. 15, 257 (2017).

17. Hou, J. K. et al. Adenanthin targets peroxiredoxin $1 / \|$ to kill hepatocellular carcinoma cells. Cell Death Dis. 5, e1400 (2014).

18. Wu, B. et al. Peroxiredoxin-2 nitrosylation facilitates cardiomyogenesis of mouse embryonic stem cells via XBP-1s/PI3K pathway. Free Radic. Biol. Med. 97, 179-191 (2016).

19. Zeng, M. et al. Effects of ghrelin on iNOS-derived NO promoted LPS-induced pulmonary alveolar epithelial A549 cells apoptosis. Cell. Physiol. Biochem. 49, 1840-1855 (2018).

20. Hou, J. et al. Gene expression-based classification of non-small cell lung carcinomas and survival prediction. PLoS ONE 5, e10312 (2010).

21. Fang, J., Nakamura, T., Cho, D. H., Gu, Z. \& Lipton, S. A. S-nitrosylation of peroxiredoxin 2 promotes oxidative stress-induced neuronal cell death in Parkinson's disease. Proc. Natl Acad. Sci. USA 104, 18742-18747 (2007).

22. Zhou, S. et al. PRDX2 protects hepatocellular carcinoma SMMC-7721 cells from oxidative stress. Oncol. Lett. 12, 2217-2221 (2016).

23. Mullen, L., Hanschmann, E. M., Lillig, C. H., Herzenberg, L. A. \& Ghezzi, P. Cysteine oxidation targets peroxiredoxins 1 and 2 for exosomal release through a novel mechanism of redox-dependent secretion. Mol. Med. 21, 98-108 (2015).
24. Saito, S. et al. Compound $C$ prevents the unfolded protein response during glucose deprivation through a mechanism independent of AMPK and BMP signaling. PLOS ONE 7, e45845 (2012).

25. Chao, L. C. \& Tontonoz, P. SIRT1 regulation-it ain't all NAD. Mol. Cell 45, 9-11 (2012).

26. Lee, C. W. et al. AMPK promotes p53 acetylation via phosphorylation and inactivation of SIRT1 in liver cancer cells. Cancer Res. 72, 4394-4404 (2012).

27. Shinozaki, S. et al. Inflammatory stimuli induce inhibitory S-nitrosylation of the deacetylase SIRT1 to increase acetylation and activation of p53 and p65. Sci. Signal 7, a106 (2014).

28. Luo, J. et al. Negative control of p53 by Sir2alpha promotes cell survival under stress. Cell 107, 137-148 (2001).

29. Finkel, T., Deng, C. X. \& Mostoslavsky, R. Recent progress in the biology and physiology of sirtuins. Nature 460, 587-591 (2009).

30. Han, M. K. et al. SIRT1 regulates apoptosis and Nanog expression in mouse embryonic stem cells by controlling p53 subcellular localization. Cell Stem Cell 2, 241-251 (2008)

31. Maehama, T., Taylor, G. S. \& Dixon, J. E. PTEN and myotubularin: novel phosphoinositide phosphatases. Annu. Rev. Biochem. 70, 247-279 (2001).

32. Ni, Y. G. et al. FoxO transcription factors activate Akt and attenuate insulin signaling in heart by inhibiting protein phosphatases. Proc. Natl Acad. Sci. USA 104, 20517-20522 (2007).

33. Jeon, H. K. Choi, S. U. \& Jung, N. P. Association of the ERK1/2 and p38 kinase pathways with nitric oxide-induced apoptosis and cell cycle arrest in colon cancer cells. Cell Biol. Toxicol. 21, 115-125 (2005).

34. Marozkina, N. V. et al. S-nitrosoglutathione reductase in human lung cancer. Am. J. Respir. Cell Mol. Biol. 46, 63-70 (2012).

35. Kim, J. et al. Regulation of STAT3 and NF-kappaB activations by S-nitrosylation in multiple myeloma. Free Radic. Biol. Med. 106, 245-253 (2017).

36. Lu, W. et al. Peroxiredoxin 2 is upregulated in colorectal cancer and contributes to colorectal cancer cells' survival by protecting cells from oxidative stress. Mol. Cell. Biochem. 387, 261-270 (2014).

37. $\mathrm{Xu}$, J. et al. Knockdown of PRDX2 sensitizes colon cancer cells to 5-FU by suppressing the PI3K/AKT signaling pathway. Biosci. Rep. 37, pii: BSR20160447 (2017).

38. Feng, J. et al. Overexpression of peroxiredoxin 2 inhibits TGF-beta1-induced epithelial-mesenchymal transition and cell migration in colorectal cancer. Mol. Med. Rep. 10, 867-873 (2014).

39. Khan, M., Dhammu, T. S., Matsuda, F., Singh, A. K. \& Singh, I. Blocking a vicious cycle nNOS/peroxynitrite/AMPK by S-nitrosoglutathione: implication for stroke therapy. BMC Neurosci. 16, 42 (2015).

40. Schaffer, B. E. et al. Identification of AMPK phosphorylation sites reveals a network of proteins involved in cell invasion and facilitates large-scale substrate prediction. Cell Metab. 22, 907-921 (2015)

41. Frank, S., Stallmeyer, B., Kampfer, H., Schaffner, C. \& Pfeilschifter, J. Differential regulation of vascular endothelial growth factor and its receptor fms-liketyrosine kinase is mediated by nitric oxide in rat renal mesangial cells. Biochem. J. 338, 367-374 (1999). (Pt 2).

42. Eu, J. P., Liu, L., Zeng, M. \& Stamler, J. S. An apoptotic model for nitrosative stress. Biochemistry 39, 1040-1047 (2000).

43. Low, F. M., Hampton, M. B., Peskin, A. V. \& Winterbourn, C. C. Peroxiredoxin 2 functions as a noncatalytic scavenger of low-level hydrogen peroxide in the erythrocyte. Blood 109, 2611-2617 (2007). 